\title{
Sexual dysfunction among youth: an overlooked sexual health concern
}

\author{
Caroline Moreau ${ }^{1,2}$, Anna E Kågesten ${ }^{1 *}$ (D) and Robert Wm Blum ${ }^{1}$
}

\begin{abstract}
Background: There is growing recognition that youth sexual health entails a broad range of physical, emotional and psychosocial responses to sexual interactions, yet little is known about sexual dysfunctions and well being in youth populations. This study explored sexual dysfunctions among youth and its associations with other domains of sexual health. Sexual dysfunctions were defined as: problems related to orgasm, pain during intercourse, lack of sexual desire or sexual pleasure.

Methods: Data were drawn from the 2010 French national sexual and reproductive health survey comprising a random sample of 2309 respondents aged 15-24 years. The current analysis included 842 females and 642 males who had sexual intercourse in the last 12 months. Chi square tests were used to test for differences in sexual dysfunctions by sex and explore associations with other domains of sexual health.

Results: Half of females (48\%) reported at least one sexual dysfunction versus $23 \%$ of males. However, over half (57\%) of youth reporting at least one dysfunction did not consider this to hinder their sexuality. Altogether, $31 \%$ of females cited at least one sexual dysfunction hindering their sexuality-more than three times the $9 \%$ of males. Sexual dysfunction was strongly and inversely related to sexual satisfaction for both males and females and additionally to a recent diagnosis of STI or unintended pregnancy for females. Sexual dysfunctions hindering sexuality were also correlated with a history of unintended pregnancy among males.

Conclusion: While most youth in France enjoy a satisfying sexual life, sexual dysfunction is common, especially among females. Public health programs and clinicians should screen for and address sexual dysfunction, which substantially reduce youth sexual wellbeing.
\end{abstract}

Keywords: Sexual dysfunction, Sexual health, Youth, Adolescents, France

\section{Background}

The World Health Organization (WHO) defines sexual health as a continuum of physical, psychological, and socio-cultural wellbeing associated with sexuality [1]. Although a growing body of work addresses the complex interrelation of the different domains of sexual health including aspects of sexual wellbeing among adult populations, research on these topics among youth remains scarce. Rather, sexual health research among youth has traditionally taken a risk reduction perspective, mostly concentrating on sexually transmitted infections (STIs) including HIV, unintended pregnancy, and sexual

\footnotetext{
* Correspondence: akaagesten@jhu.edu

${ }^{1}$ Department of Population, Family and Reproductive Health, Johns Hopkins Bloomberg School of Public Health, 615 North Wolfe Street, Baltimore, MD 21205, USA

Full list of author information is available at the end of the article
}

coercion due to their significant contributions to disability adjusted life years for youth [2].

There is growing recognition however, that youth sexual health entails a broader range of physical, emotional and psychosocial responses to sexual interactions than just physical morbidities [3, 4]. Studies in adult populations have revealed high prevalence of sexual dysfunction $[5,6]$, which, according to the International Classification of Disease (ICD-10) [7], encompasses a spectrum of symptoms including lack of sexual desire, lack of sexual pleasure, failure of genital response, orgasmic dysfunction, premature ejaculation and dyspareunia $[2,6]$. This symptomatology follows the Masters and Johnson [8] and Kaplan [9] frameworks of the three-phase model of sexual response (desire, arousal, and orgasm), with the addition of sexual pain. Adding to the symptomatology 
itself, the Diagnostic and Statistical Manual of Mental Disorders (DSM-V) specifies the duration and severity of symptoms to distinguish sexual dysfunction from variation of normal sexual response and the clinical significance of these symptoms $[10,11]$. The addition of clinical distress reflects an ongoing debate contrasting a bio-medical model of sexual functioning focusing on physiological response with a psychosocial model that also considers the psychosocial aspects of sexuality including the social expectations of sexual relations $[4,11]$.

Measuring sexual dysfunction in population-based surveys is challenging given the sensitive nature of the topic, time constraints and potential recall errors [12]. The most widely used instruments are the Female Sexual Function Index (FSFI) (19 items) for females [13] and the International Index of Erectile Function (IIEI) for males [14]. The FSFI instrument only covers a 4-week period, failing to distinguish transient from prolonged symptomatology among females while the IIEI instrument only focuses on erectile dysfunction omitting other functional dimensions of sexual activity among males [6]. None of these instruments assess aspects of sexual distress. While definitions, measures and sampling strategies vary, population based surveys consistently report that the nature and frequency of sexual dysfunctions vary by sex, with females mostly citing hypoactive sexual desire and orgasm while males mostly report premature ejaculation and erectile dysfunction $[5,15]$.

Furthermore, evidence indicates that many individuals experiencing sexual dysfunctions are not distressed by these symptoms [11]. While sexual dysfunctions emerge early in the sexual trajectories of adults who present with such problems [16], little is known about sexual dysfunctions and their consequences on youth sexual health $[15,17]$. The few studies conducted among youth reveal high levels of sexual dysfunction, including pain, lack of desire and failure of genital response [15]. A recent study by Sullivan [18] among 411 Canadian youth aged 16 to 21 years indicated that half of the participants reported at least one sexual functioning complaint. While sexual dysfunctions were frequent, distress related to such dysfunctions was less prevalent: half of those with sexual complaints suffered clinically significant sexual related distress [18].

Sullivan's study provides a thorough investigation of sexual functioning using validated instruments of male and female sexual functioning [18]. Yet, the small convenience sample of adolescents limits the generalizability of the findings; and the focus on sexual dysfunction and sexual distress alone does not allow an exploration of the interrelation of sexual functioning with other domains of sexual health.
Recent studies conducted in the Great Britain [19] and Flanders, Belgium [20] seek to address some of these gaps, assessing sexual functioning in larger samples of the general population. While the Flanders study reports age-specific prevalence of sexual difficulties and associated distress, the study draws inferences from a convenience sample of the population (online survey advertised through media channels), which raises concern regarding the generalizability of their findings [20]. In contrast, The National Survey of Sexual Attitudes and Lifestyles (Natsal) study in Great Britain assesses sexual functioning among male and female youth, using a nationally representative probability sample [19]. The Natsal survey however uses a different measure of sexual function problems [12] based on a conceptual framework that includes both psycho-physiological and relational aspects of sexual functioning [21]. The Natsal sexual functioning instrument excludes measures of severity and distress, based on the psychometric proprieties of the scale [12]. In addition, questions cover a short period of time (three months) [12].

Building on a more conventional psycho-social and physiological conceptualization of sexual functioning, the present study aims to provide new information on the prevalence of youth sexual dysfunction and its consequences on sexuality in France, and the intersection between sexual dysfunctions with other domains of sexual health, including sexual satisfaction, STIs and unintended pregnancies.

The current study addresses three main questions. What are the patterns of youth sexual dysfunctions and to what extent do young people consider such dysfunctions to affect their sexuality? How do these patterns differ by sex? How are youth sexual dysfunctions related to other domains of sexual health? In this article we refer to sex differences in behaviours and outcomes as we compare males and females without accounting for their gender identity, because gender identity was not assessed in the FECOND study. However, we acknowledge that much of the sex differences that are reported are not only biologically, but also socially driven.

\section{Methods}

\section{Study design and sample}

Data were drawn from the 2010 French national sexual and reproductive health survey, FECOND, comprising 8475 individuals aged 15 to 49 years residing in France. Participants were selected following a two-stage probability sampling method. Phone numbers (including both landline and cell-phones) were generated using random digit dialling. One individual per phone number was selected for participation. The refusal rate was estimated at $20 \%$ [22]. 
After verbal consent, participants responded to a 40min telephone questionnaire. The FECOND study was approved by the French Commission Nationale de l'Informatique et des Libertés and the current secondary analysis was approved by the Bloomberg School of Public Health Institutional Review Board at Johns Hopkins University.

The present analysis was restricted to respondents aged 15 to 24 years $(n=2309)$ who reported ever having had sexual intercourse $(n=944$ females and $n=731$ males). Sexual intercourse was assessed as a positive response to any of two questions "Have you ever had sexual intercourse with a woman?" and "Have you ever had sexual intercourse with a man?" The definition of sexual intercourse did not distinguish between different types of sexual practices. Questions on sexual difficulties and satisfaction were only asked of respondents who reported having had sexual intercourse in the last 12 months ( $n=886$ females and $n=679$ males). We further excluded participants who stopped responding to the survey before the sexual health module $(n=41 \mathrm{fe}-$ males and $n=32$ males). Our final sample comprised 1484 participants ( $n=842$ females and $n=642$ males).

\section{Measures}

Topics explored in the multi-thematic FECOND study included socio-demographic status, reproductive histories, past and current sexual health indicators. The key outcome of interest in the present study was sexual dysfunction and sexual dysfunction hindering sexuality in the past 12 months, assessed through a set of five questions for females and six questions for males. These questions were derived from the last national sexual health survey "The Context of Sexuality in France (CSF)" conducted in France in 2006 for comparative purposes [23]. The CSF sexual dysfunction module was based upon the the ICD-10 classification of sexual dysfunction [7]. The questions examined the following symptoms: lack of sexual desire, lack of pleasure during intercourse, difficulty reaching orgasm and pain during intercourse. In addition, females were asked about vaginal dryness while males were asked about problems of erections and premature ejaculation. Response options assessing the frequency of each sexual difficulty in the last 12 months ranged from "often", "sometimes", "rarely", or "never". We examined each sexual difficulty separately and constructed a prevalence indicator summarizing the number of problems reported (none, $1,>1$ ). This indicator was based on the four most common sexual problems that were reported among males and females in order to compare results by sex. Following the CSF survey module [23], which not only assessed the frequency of sexual difficulties but how such difficulties related to an individual's assessment of their own sexuality, respondents were also asked if each of these four components "constituted a problem for their own sexuality". Based on this information, we constructed a revised set of measures of sexual dysfunctions hindering sexuality in the rest of the article.

We further investigated the association between sexual dysfunctions with four other domains of sexual health. First, history of STI in the last five years was assessed by a question asking about having had an STI during this time period. If respondents indicated having had an STI in the last five years, they were further asked if the infection were "herpes", "mycosis" (thrush) or another infectious agent, and in the later case they were asked to provide the name of the infectious agent. Thrush was excluded from the definition of STIs in this analysis. Secondly, lifetime experience of an unintended pregnancy was a constructed measure summarizing participant's pregnancy intentions at the time of each pregnancy. Third, forced sexual intercourse in the last 12 months was assessed with a single question asking if the respondent had had forced sexual intercourse against his/her will in the last 12 months (often, sometimes, rarely or never). A dichotomous measure was constructed opposing never to all other responses. Lastly, youth were also asked about sexual satisfaction at the time of the survey, operationalized as "very satisfied", "rather satisfied", "rather not satisfied" or "not satisfied at all" with current sexual life. We also explored the association between sexual dysfunctions and frequency of intercourse in the last four weeks. All measures were self-reported.

\section{Statistical analysis}

Descriptive statistics were used to explore sex differences in sexual dysfunctions and assess the extent to which each of these dysfunctions hindered sexuality among youth. Using a prevalence indicator of number of reported sexual dysfunctions, we then examined the associations across sexual dysfunctions and other domains of sexual health, including sexual satisfaction, sexual violence, STI, unintended pregnancy and frequency of sexual intercourse. We performed the same analysis assessing associations between sexual dysfunction hindering sexuality and other indicators of sexual health. Chi square tests were used to explore differences in sexual dysfunctions and sexual dysfunctions hindering sexuality by sex and to unveil associations between sexual dysfunctions indicators with other domains of sexual health.

\section{Results}

The mean age of respondents was 20.2 years with no difference by sex $(p=0.23)$. Most respondents had a partner at the time of the survey, with a greater proportion 
of females in a cohabitating partnership than males (31\% versus $18 \%$ ) (Table 1 ). The mean reported age at sexual debut was 16.5 years for females and 15.8 years for males. Males reported a greater number of lifetime sexual partners than females $(6.4$ versus $3.6, \mathrm{p}<0.001)$. Frequency of intercourse was equally distributed by sex, with $23 \%$ of males and $17 \%$ of females reporting no sexual relations in the last 4 weeks. Four percent of respondents reported ever having a same sex partner, with no difference by sex. There were no significant sex differences in the proportion of respondents reporting a history of unintended pregnancy or an STI in the last 5 years. Three percent of respondents reported an experience of forced sex in the last 12 months, with no difference by sex.

\section{Patterns of youth sexual dysfunctions and sexual dysfunctions hindering sexuality}

Female youth were more likely to report sexual dysfunction than their male counterparts (Table 2). Lack of sexual desire and difficulty reaching orgasm were the most commonly cited problems for females: $26 \%$ and $31 \%$ indicated that these problems occurred on a regular basis (often or sometimes) versus $11 \%$ and $8 \%$ of males ( $p<$ 0.001). Pain during sexual intercourse was also more frequent among females: $21 \%$ cited that this difficulty occurred often or sometimes versus $4 \%$ of males $(p<$ 0.001 ). In addition, $21 \%$ of males indicated that they regularly experienced premature ejaculation while a minority (4\%) reported problems of erection. One in 11 females (9\%) indicated they experienced vaginal dryness on a regular basis.

Using the prevalence indicator of combined sexual dysfunctions common to both sexes, results show that half of females (53\%) reported no sexual dysfunctions, while one in five $(21 \%)$ indicated more than one dysfunction occurring "often" or "sometimes" in the last 12 months. For males, $80 \%$ cited no dysfunction while $4 \%$ cited more than one dysfunction $(p<0.001)$. The number of dysfunctions reported did not significantly vary by age with $21 \%$ of adolescent females $15-19$ years and $4 \%$ of adolescent males citing more than one dysfunction.

Female youth were more likely to report that a sexual dysfunction affected their own sexuality than male youth. Almost one in three females (31\%) cited at least one sexual dysfunction causing a problem for their own sexuality as compared to $9 \%$ of males $(p<0.001)$, with no significant differences by age. This sex difference was due primarily to the higher prevalence of sexual dysfunctions (twice as high among females than males) and to a lesser extent to differences in whether these symptoms were perceived to hinder sexuality. Specifically, 59\% of all females reporting at least one symptom considered it posed a problem for their own sexuality versus 39\% of males $(p=0.02)$. The extent to which dysfunctions caused a problem for one's sexuality varied by symptom: $44 \%$ to $77 \%$ of sexual dysfunction symptoms among females and $34 \%$ to $52 \%$ among males were considered a to cause a problem for one's sexuality (data not shown). Pain during sexual intercourse was most likely to hinder sexuality for both sexes, followed by problems of erection for males and vaginal dryness for females (Table 2).

\section{Relationship between sexual dysfunctions and other domains of sexual health}

Table 3 presents the associations between sexual dysfunctions or sexual dysfunctions hindering sexuality that were common to both sexes (lack of sexual desire, lack of pleasure during intercourse, difficulty reaching orgasm and pain during intercourse) and other domains of sexual health. Results indicate a strong association between sexual dysfunctions and sexual satisfaction: $74 \%$ of females were very satisfied with their current sexual life when they reported no sexual dysfunction versus $36 \%$ of those with more than one dysfunction $(p<$ 0.001). In the absence of dysfunction, half of males (54\%) were very satisfied with their sexual life but that dropped to about one third (29\%) when they reported more than one sexual dysfunction $(p<0.001)$. Associations were stronger when respondents reported a sexual dysfunction hindering their own sexuality. Sexual dysfunction alone was not associated with frequency of intercourse, however sexual dysfunction hindering one's sexuality was related to frequency of intercourse among males, but not among females. Specifically, over half of males (53\%) reported having had no sexual intercourse in the last four weeks if they suffered more than one sexual dysfunction hindering their sexuality, more than double that of males who either reported no or one sexual dysfunction hindering their sexuality $(p=0.002)$. While the overall association between sexual dysfunction and a recent STI diagnosis among females was not significant, further analysis indicated that females reporting more than one sexual dysfunction were more likely to report a recent diagnosis of STI as compared to females without such problems ( $4 \%$ versus $\%, p=0.03$ ). This association was borderline significant in the presence of more than one dysfunction hindering one's sexuality ( $4 \%$ versus $2 \%, P=0.07$ ). In addition, sexual dysfunction was related to a history of unintended pregnancy among female youth $(p=0.05)$, and the presence of more than one dysfunction hindering sexuality was borderline related to unintended pregnancy among females $(p=0.06)$. Males who reported more than one sexual dysfunction as opposed to none were more likely to report an unintended pregnancy (19\% versus $7 \% p=0.01)$; this association was highly significant when considering sexual 
Table 1 Socio-demographic characteristics and sexual health indicators for sexually experienced youth $(n=1484)$

\begin{tabular}{|c|c|c|c|}
\hline & $\begin{array}{l}\text { Females } n= \\
842\end{array}$ & $\begin{array}{l}\text { Males } n= \\
642\end{array}$ & $p$ \\
\hline Age & & & 0.75 \\
\hline $15-19$ years & $45 \%$ & $46 \%$ & \\
\hline 20-24 years & $55 \%$ & $54 \%$ & \\
\hline Relationship status & & & $<0.001$ \\
\hline No partner & $23 \%$ & $36 \%$ & \\
\hline Non-cohabitating partner & $45 \%$ & $45 \%$ & \\
\hline Cohabitating partner & $31 \%$ & $18 \%$ & \\
\hline Education level & & & 0.03 \\
\hline$<$ High school graduation & $45 \%$ & $52 \%$ & \\
\hline High school graduation & $35 \%$ & $33 \%$ & \\
\hline$>$ High school & $20 \%$ & $15 \%$ & \\
\hline Professional situation & & & 0.001 \\
\hline Working & $28.6 \%$ & $41 \%$ & \\
\hline Student & $58.3 \%$ & $47 \%$ & \\
\hline Unemployed & $10.2 \%$ & $10 \%$ & \\
\hline Other & $2.9 \%$ & $1 \%$ & \\
\hline Country of birth & & & 0.28 \\
\hline France & $92.6 \%$ & $94 \%$ & \\
\hline Foreign country & $7 \%$ & $6 \%$ & \\
\hline $\begin{array}{l}\text { Mean (SD) age at first sexual } \\
\text { intercourse }\end{array}$ & $\begin{array}{l}16.5(16.4- \\
16.7)\end{array}$ & $\begin{array}{l}15.8(15.6- \\
16.0)\end{array}$ & $<0.001$ \\
\hline Sexual orientation & & & 0.21 \\
\hline Heterosexual & $96 \%$ & $97 \%$ & \\
\hline Bisexual & $3 \%$ & $1 \%$ & \\
\hline Homosexual & $1 \%$ & $2 \%$ & \\
\hline Mean (SD) number of lifetime & $3.6(3.3-3.9)$ & $6.4(5.7-7.0)$ & $<0.001$ \\
\hline
\end{tabular}
partners

$\mathrm{Nr}$ of partners last 12 months.

1 partner
2 to 4 partners
$5+$ partners
Missing

Ever unintended pregnancy

STI in the last 5 years

Forced sex last 12 months

Satisfaction with sexual life

Very satisfied

Rather satisfied

Little satisfied

Not satisfied at all

Frequency of sexual acts last 4 weeks

No acts
Table 1 Socio-demographic characteristics and sexual health indicators for sexually experienced youth ( $n=1484)$ (Continued)

\begin{tabular}{lll}
\hline $1-4$ acts & $27 \%$ & $24 \%$ \\
$5-9$ acts & $17 \%$ & $15 \%$ \\
$10+$ acts & $39 \%$ & $39 \%$ \\
\hline
\end{tabular}

dysfunction hindering sexuality (37\% versus $7 \%, p$ $<0.001)$. None of the associations were significant for either males or females when examining the relation between sexual dysfunctions and forced sexual intercourse in the last 12 months. Taken together, there were no sex differences in the associations observed.

Table 4 shows the correlations between sex-specific sexual dysfunctions and other sexual health indicators. None of the sex-specific sexual dysfunctions were related to frequency of sexual intercourse, STI, forced sex or unintended pregnancy. Problems of erection and premature ejaculation were both related to sexual satisfaction especially if they were considered to hinder one's sexuality while there was no significant association between vaginal dryness and sexual satisfaction among females.

\section{Discussion}

While a majority of sexually experienced youth aged 1524 years in France enjoy a satisfying sexual life (93\% of females and $92 \%$ of males reported that they were satisfied or very satisfied with their sexual life), this study indicates that sexual dysfunctions are common although for many young people such symptoms are not reported to be a problem for their own sexuality. Specifically, we found that half of females and a third of males reported at least one sexual dysfunction; however, only a third of females and $9 \%$ of males reported that the dysfunctions hindered their sexuality.

Our estimates are difficult to compare to existing literature, since such reports are scarce in this age group [17], use different populations or different survey instruments and different time frames to assess the prevalence of sexual dysfunctions and sexual distress [15]. Compared to a recent Flemish study conducted among a convenience samples of 15000 women aged 16 to 74 years recruited online and responding to Sexual Functioning Scale questionnaire, our study showed similar levels of vaginal dryness and absence/delayed orgasm alone among the youth population but lower prevalence rates of lack of desire and dyspareunia [20]. The proportion of sexual problems causing distress was generally above $50 \%$ in the Flanders study [20], which is higher than our estimates of sexual dysfunction hindering sexuality. However, sexual distress and the relation of sexual dysfunction to sexuality are two different constructs, the later extending far beyond sexual practice to encompass 
Table 2 Percentage of youth reporting specific sexual difficulties and percentage reporting sexual difficulties hindering their sexuality

\begin{tabular}{|c|c|c|c|c|c|c|c|c|}
\hline \multirow[b]{2}{*}{ Type of dysfunction } & \multicolumn{4}{|c|}{ All sexual dysfunctions ${ }^{a}$} & \multicolumn{4}{|c|}{ Sexual dysfunctions hindering sexuality ${ }^{b}$} \\
\hline & Frequency & $\begin{array}{l}\text { Females } n= \\
842\end{array}$ & $\begin{array}{l}\text { Males } n= \\
642\end{array}$ & $p$ & $\begin{array}{l}\text { Type of dysfunction hindering } \\
\text { sexuality }\end{array}$ & $\begin{array}{l}\text { Females } n= \\
842\end{array}$ & $\begin{array}{l}\text { Males } n= \\
642\end{array}$ & $p$ \\
\hline \multirow[t]{4}{*}{ Difficulty reaching orgasm } & Often & $7 \%$ & $1 \%$ & \multirow[t]{4}{*}{$<0.001$} & \multirow[t]{4}{*}{ Difficulty reaching orgasm } & \multirow[t]{4}{*}{$12 \%$} & \multirow[t]{4}{*}{$3 \%$} & \multirow[t]{4}{*}{$<0.001$} \\
\hline & Sometimes & $21 \%$ & $6 \%$ & & & & & \\
\hline & Rarely & $19 \%$ & $10 \%$ & & & & & \\
\hline & Never & $53 \%$ & $83 \%$ & & & & & \\
\hline \multirow[t]{4}{*}{ Lack of sexual desire } & Often & $4 \%$ & $1 \%$ & \multirow[t]{4}{*}{$<0.001$} & \multirow[t]{4}{*}{ Lack of sexual desire } & \multirow[t]{4}{*}{$13 \%$} & \multirow[t]{4}{*}{$4 \%$} & \multirow[t]{4}{*}{$<0.001$} \\
\hline & Sometimes & $20 \%$ & $9 \%$ & & & & & \\
\hline & Rarely & $26 \%$ & $18 \%$ & & & & & \\
\hline & Never & $50 \%$ & $72 \%$ & & & & & \\
\hline \multirow[t]{4}{*}{ Pain during intercourse } & Often & $4 \%$ & $0 \%$ & \multirow[t]{4}{*}{$<0.001$} & \multirow[t]{4}{*}{ Pain during intercourse } & \multirow[t]{4}{*}{$16 \%$} & \multirow[t]{4}{*}{$2 \%$} & \multirow[t]{4}{*}{$<0.001$} \\
\hline & Sometimes & $18 \%$ & $5 \%$ & & & & & \\
\hline & Rarely & $21 \%$ & $8 \%$ & & & & & \\
\hline & Never & $58 \%$ & $88 \%$ & & & & & \\
\hline \multirow{4}{*}{$\begin{array}{l}\text { Lack of pleasure during } \\
\text { intercourse }\end{array}$} & Often & $2 \%$ & $2 \%$ & \multirow[t]{4}{*}{$<0.001$} & \multirow[t]{4}{*}{ Lack of pleasure during intercourse } & \multirow[t]{4}{*}{$10 \%$} & \multirow[t]{4}{*}{$3 \%$} & \multirow[t]{4}{*}{$<0.001$} \\
\hline & Sometimes & $14 \%$ & $6 \%$ & & & & & \\
\hline & Rarely & $26 \%$ & $18 \%$ & & & & & \\
\hline & Never & $59 \%$ & $74 \%$ & & & & & \\
\hline \multirow[t]{4}{*}{ Vaginal dryness } & Often & $1 \%$ & - & & Vaginal dryness & $7 \%$ & - & \\
\hline & Sometimes & $8 \%$ & - & & & & & \\
\hline & Rarely & $9 \%$ & - & & & & & \\
\hline & Never & $81 \%$ & - & & & & & \\
\hline Problem maintaining an & Often & - & $1 \%$ & & Problem maintaining an erection & - & $2 \%$ & \\
\hline & Sometimes & - & $4 \%$ & & & & & \\
\hline & Rarely & - & $11 \%$ & & & & & \\
\hline & Never & - & $85 \%$ & & & & & \\
\hline Premature ejaculation & Often & - & $2 \%$ & & Premature ejaculation & - & $10 \%$ & \\
\hline & Sometimes & - & $18 \%$ & & & & & \\
\hline & Rarely & - & $33 \%$ & & & & & \\
\hline & Never & - & $48 \%$ & & & & & \\
\hline Nr of sexual dysfunctions & None & $48 \%$ & $77 \%$ & $<0.001$ & Nr of sexual dysfunctions hindering & $69 \%$ & $91 \%$ & $<0.001$ \\
\hline & 1 & $29 \%$ & $17 \%$ & & sexuality & $18 \%$ & $7 \%$ & \\
\hline & $>1$ & $23 \%$ & $6 \%$ & & & $13 \%$ & $2 \%$ & \\
\hline
\end{tabular}

${ }^{a}$ Percentage of youth reporting sexual dysfunctions (often, sometimes, rarely, never) irrespective of whether these problems cause distress

${ }^{b}$ Percentage of youth reporting sexual dysfunctions hindering sexuality (yes/no)

notions of identity, attitudes and feelings towards sex. In addition, the sexual distress measure of the Flemish study criteria included both personal and partner distress as recommended in the DSM-IV classification, which may have inflated their estimates, as interpersonal distress is no longer a criterion for sexual dysfunction in the DSM-V [10]. Differences in sampling method (convenience sample in the Flemish study versus probability sampling in the FECOND study) may also account for some of the differences observed. The Natsal study in
Britain used an extended definition of sexual functioning (incorporating both psycho-physiological and relational aspects of sexual functioning) and a short time frame to assess sexual dysfunction (3 months) [12]. In addition, the Natsal measure did not specifically assess the overall consequences of sexual dysfunctions on the respondent's own sexuality. While these differences preclude meaningful comparisons with our current study, the Natsal study also reported that a significant proportion of youth had low sexual function (14\% of young women and 13\% of young 
Table 3 Associations between number of sexual dysfunctions ${ }^{a}$ and other domains of sexual health among youth

\begin{tabular}{|c|c|c|c|c|c|c|c|c|}
\hline & \multicolumn{8}{|c|}{ Nr of sexual dysfunctions } \\
\hline & \multicolumn{4}{|c|}{ Females $n=842$} & \multicolumn{4}{|c|}{ Males $n=642$} \\
\hline & None & 1 & $>1$ & $p$ & None & 1 & $>1$ & $p$ \\
\hline Intercourse frequency last 4 weeks & & & & 0.41 & & & & 0.34 \\
\hline None & $18 \%$ & $15 \%$ & $18 \%$ & & $22 \%$ & $20 \%$ & $38 \%$ & \\
\hline $1-4$ acts & $23 \%$ & $29 \%$ & $32 \%$ & & $23 \%$ & $27 \%$ & $21 \%$ & \\
\hline $5-9$ acts & $18 \%$ & $16 \%$ & $17 \%$ & & $14 \%$ & $19 \%$ & $16 \%$ & \\
\hline $10+$ acts & $41 \%$ & $39 \%$ & $33 \%$ & & $41 \%$ & $34 \%$ & $25 \%$ & \\
\hline Sexual satisfaction & & & & $<0.001$ & & & & $<0.001$ \\
\hline Very satisfied & $74 \%$ & $53 \%$ & $36 \%$ & & $54 \%$ & $44 \%$ & $29 \%$ & \\
\hline Rather satisfied & $22 \%$ & $40 \%$ & $51 \%$ & & $39 \%$ & $51 \%$ & $46 \%$ & \\
\hline Not very satisfied & $3 \%$ & $5 \%$ & $8 \%$ & & $5 \%$ & $3 \%$ & $18 \%$ & \\
\hline Not at all satisfied & $1 \%$ & $2 \%$ & $5 \%$ & & $2 \%$ & $2 \%$ & $6 \%$ & \\
\hline Forced sex last 12 months & $1 \%$ & $3 \%$ & $5 \%$ & 0.27 & $4 \%$ & $6 \%$ & $4 \%$ & 0.55 \\
\hline STI last 5 years & $1 \%$ & $2 \%$ & $4 \%$ & 0.09 & $1 \%$ & $0 \%$ & $2 \%$ & 0.50 \\
\hline \multirow[t]{4}{*}{ Ever unintended pregnancy } & $11 \%$ & $6 \%$ & $15 \%$ & 0.05 & $7 \%$ & $8 \%$ & $19 \%$ & 0.07 \\
\hline & \multicolumn{8}{|c|}{$\begin{array}{l}\mathrm{Nr} \text { of sexual dysfunctions } \\
\text { hindering sexuality }\end{array}$} \\
\hline & \multicolumn{4}{|c|}{ Females $n=842$} & \multicolumn{4}{|c|}{ Males $n=642$} \\
\hline & None & 1 & $>1$ & $p$ & None & 1 & $>1$ & $p$ \\
\hline Intercourse frequency last 4 weeks & & & & 0.82 & & & & 0.002 \\
\hline None & $18 \%$ & $15 \%$ & $17 \%$ & & $22 \%$ & $23 \%$ & $53 \%$ & \\
\hline $1-4$ acts & $27 \%$ & $25 \%$ & $32 \%$ & & $22 \%$ & $48 \%$ & $10 \%$ & \\
\hline $5-9$ acts & $18 \%$ & $18 \%$ & $15 \%$ & & $15 \%$ & $11 \%$ & $16 \%$ & \\
\hline $10+$ acts & $38 \%$ & $43 \%$ & $35 \%$ & & $41 \%$ & $18 \%$ & $21 \%$ & \\
\hline Sexual satisfaction & & & & $<0.001$ & & & & $<0.001$ \\
\hline Very satisfied & $69 \%$ & $47 \%$ & $24 \%$ & & $53 \%$ & $26 \%$ & $17 \%$ & \\
\hline Rather satisfied & $27 \%$ & $47 \%$ & $57 \%$ & & $40 \%$ & $63 \%$ & $50 \%$ & \\
\hline Not very satisfied & $3 \%$ & $5 \%$ & $13 \%$ & & $5 \%$ & $11 \%$ & $17 \%$ & \\
\hline Not at all satisfied & $1 \%$ & $1 \%$ & $7 \%$ & & $2 \%$ & $0 \%$ & $16 \%$ & \\
\hline Forced sex last 12 months & $2 \%$ & $4 \%$ & $4 \%$ & 0.48 & $4 \%$ & $4 \%$ & $0 \%$ & 0.81 \\
\hline STI last 5 years & $2 \%$ & $2 \%$ & $4 \%$ & 0.25 & $1 \%$ & $0 \%$ & $0 \%$ & 0.76 \\
\hline Ever unintended pregnancy & $10 \%$ & $9 \%$ & $16 \%$ & 0.21 & $7 \%$ & $9 \%$ & $37 \%$ & $<0.001$ \\
\hline
\end{tabular}

${ }^{a}$ Sexual dysfunctions include: pain during intercourse, lack of sexual desire, problems reaching orgasm, lack of pleasure during intercourse

men aged 16 to 24 years) [19], calling our attention to address sexual functioning problems across the lifespan.

In our study a substantial proportion of males and females did not consider sexual dysfunctions to be problematic for their own sexuality (41\% of females and $61 \%$ of males). The gap between symptomatology and related distress is the focus of much debate regarding the diagnostic criteria for sexual dysfunctions [11]. The proponents of a medical model (reflected in the ICD-10 classification) argue that the diagnostic criteria for sexual dysfunction should not include its clinical or psychosocial consequences, while others referring to a socially inspired model of sexual functioning consider distress as an indicator of sexual dysfunction (DSM-V), drawing attention to the functional utility of the definition [11]. This later perspective has gained momentum in the advent of marketing of drugs for erectile dysfunction, bearing on the medicalization of sexual health [4]. While the added value of distress to the specificity of the measure remains controversial, the subjective experiences of sexual functioning should be considered as critical elements underlying healthcare seeking behaviours. The relation of sexual functioning to one's sexuality extends beyond the notion of sexual distress by considering that sexual functioning can also affect one's sexual identity and one's attitudes and feelings related to sexual interactions. 
Table 4 Associations between sex-specific sexual dysfunctions and other dimensions of sexual health among youth

\begin{tabular}{|c|c|c|c|c|c|c|c|c|c|}
\hline & \multicolumn{3}{|c|}{$\begin{array}{l}\text { Females } \\
N=842\end{array}$} & \multicolumn{6}{|c|}{$\begin{array}{l}\text { Males } \\
N=642\end{array}$} \\
\hline & \multicolumn{3}{|c|}{ Vaginal dryness } & \multicolumn{3}{|c|}{ Problems of erection } & \multicolumn{3}{|c|}{ Premature ejaculation } \\
\hline & Yes & No & $p$ & Yes & No & p & Yes & No & $p$ \\
\hline Intercourse frequency last 4 weeks & & & 0.54 & & & 0.33 & & & 0.78 \\
\hline No acts & $13 \%$ & $17 \%$ & & $32 \%$ & $22 \%$ & & $26 \%$ & $22 \%$ & \\
\hline $1-4$ acts & $32 \%$ & $26 \%$ & & $29 \%$ & $23 \%$ & & $25 \%$ & $23 \%$ & \\
\hline $5-9$ acts & $21 \%$ & $17 \%$ & & $17 \%$ & $15 \%$ & & $13 \%$ & $15 \%$ & \\
\hline 10 acts + & $35 \%$ & $39 \%$ & & $22 \%$ & $40 \%$ & & $36 \%$ & $40 \%$ & \\
\hline Sexual satisfaction & & & 0.12 & & & 0.02 & & & 0.09 \\
\hline Very satisfied & $45 \%$ & $61 \%$ & & $39 \%$ & $51 \%$ & & $41 \%$ & $53 \%$ & \\
\hline Rather satisfied & $43 \%$ & $33 \%$ & & $40 \%$ & $42 \%$ & & $50 \%$ & $40 \%$ & \\
\hline Not very satisfied & $6 \%$ & $5 \%$ & & $12 \%$ & $5 \%$ & & $8 \%$ & $5 \%$ & \\
\hline Not at all satisfied & $4 \%$ & $2 \%$ & & $9 \%$ & $3 \%$ & & $2 \%$ & $2 \%$ & \\
\hline Forced sex last 12 months & $3 \%$ & $3 \%$ & 0.69 & $1 \%$ & $4 \%$ & 0.22 & $4 \%$ & $4 \%$ & 0.84 \\
\hline STI in the last 5 years & $1 \%$ & $2 \%$ & 0.30 & $3 \%$ & $1 \%$ & 0.20 & $1 \%$ & $1 \%$ & 0.94 \\
\hline \multirow[t]{3}{*}{ Ever unintended pregnancy } & $14 \%$ & $10 \%$ & 0.31 & $7 \%$ & $8 \%$ & 0.74 & $7 \%$ & $8 \%$ & 0.63 \\
\hline & \multicolumn{3}{|c|}{$\begin{array}{l}\text { Vaginal dryness hindering } \\
\text { sexuality }\end{array}$} & \multicolumn{3}{|c|}{$\begin{array}{l}\text { Problems of erection hindering } \\
\text { sexuality }\end{array}$} & \multicolumn{3}{|c|}{$\begin{array}{l}\text { Premature ejaculation hindering } \\
\text { sexuality }\end{array}$} \\
\hline & Yes & No & $p$ & Yes & No & $p$ & Yes & No & $p$ \\
\hline Intercourse frequency last 4 weeks & & & 0.79 & & & 0.18 & & & 0.32 \\
\hline No acts & $14 \%$ & $17 \%$ & & $38 \%$ & $22 \%$ & & $33 \%$ & $22 \%$ & \\
\hline $1-4$ acts & $31 \%$ & $27 \%$ & & $39 \%$ & $23 \%$ & & $23 \%$ & $24 \%$ & \\
\hline 5-9 acts & $21 \%$ & $17 \%$ & & $0 \%$ & $15 \%$ & & $13 \%$ & $15 \%$ & \\
\hline 10 acts+ & $34 \%$ & $39 \%$ & & $23 \%$ & $39 \%$ & & $31 \%$ & $40 \%$ & \\
\hline Sexual satisfaction & & & 0.18 & & & 0.02 & & & 0.04 \\
\hline Very satisfied & $46 \%$ & $61 \%$ & & $31 \%$ & $51 \%$ & & $37 \%$ & $52 \%$ & \\
\hline Rather satisfied & $43 \%$ & $33 \%$ & & $41 \%$ & $42 \%$ & & $50 \%$ & $41 \%$ & \\
\hline Not very satisfied & $7 \%$ & $5 \%$ & & $15 \%$ & $5 \%$ & & $12 \%$ & $5 \%$ & \\
\hline Not at all satisfied & $5 \%$ & $2 \%$ & & $13 \%$ & $2 \%$ & & $2 \%$ & $2 \%$ & \\
\hline Forced sex last 12 months & $3 \%$ & $2 \%$ & 0.58 & $3 \%$ & $4 \%$ & 0.69 & $0 \%$ & $5 \%$ & 0.15 \\
\hline STI in the last 5 years & $0 \%$ & $2 \%$ & 0.24 & $0 \%$ & $1 \%$ & 0.72 & $2 \%$ & $1 \%$ & 0.34 \\
\hline Ever unintended pregnancy & $11 \%$ & $11 \%$ & 0.96 & $3 \%$ & $8 \%$ & 0.25 & $7 \%$ & $8 \%$ & 0.76 \\
\hline
\end{tabular}

Beyond its prevalence assessments, this study contributes new knowledge in several important ways. First, our results indicate marked sex-differences in the prevalence of sexual dysfunction starting in adolescence, which were not observed in the Natsal survey in Britain [19]. However, similar findings were reported in the previous French sexual health survey (CSF survey) conducted in 2006 in a slightly older population, as women between 18 and 35 years were more likely to report sexual distress than men while the reverse was true after the age of 35 [23].

Expanding on prior work, our results further show that sexual dysfunctions are inter-correlated; $30 \%$ of females and 19\% of males who reported any dysfunction indicated more than one symptom. These sex differences in the interconnection of sexual functioning problems have been described in other studies among older populations [15] and call attention to the relational context in which sexual interactions occur. The Natsal study stresses the importance of the relational nature of sexual interactions [21], but includes the relational aspect of sexual activity within the sexual functioning scale precluding a direct investigation of the intersection of psycho-physiological and relational attributes of sexual function. Further longitudinal exploration of sexual symptoms and clusters of sexual symptoms, as well as how they affect an individual's sexuality identity, their attitudes, feeling and relational experiences of sexual activity is 
warranted to understand how dysfunctions evolve over time and across relationships.

Our third contribution highlights the intersection of sexual dysfunctions with other domains of sexual health. In particular, we found a highly negative correlation between sexual dysfunctions and sexual satisfaction, highlighting the important contribution of sexual function to youth sexual well-being. Importantly, we found that the clustering of dysfunctions was related to a history of STI among females, and increased likelihood of reporting an unintended pregnancy in both sexes. A similar correlation between low sexual function and a past history of STIs was also reported in the Natsal study, although this association was not specific to youth [19].

The current study has a number of limitations. Because of the multi-thematic nature of the FECOND study, we did not use a validated measure of sexual functioning, although our questions were drawn from the national sexual health survey conducted in France in 2006, which captured all dimensions of sexual dysfunctions assessed in the most widely used scales (Female Sexual Functioning Index [13] or the Brief Sexual Function Inventory) [24]. However, unlike validated scales that assess symptoms over a four week period and do not measure the subjective repercussions of sexual dysfunction on sexuality, our construct of sexual dysfunction (difficulties that occur often or sometimes and affect individual's sexuality over the last 12 months) is more in line with the most recent DSM-V definition of sexual dysfunction, involving symptomatology causing significant distress for a prolonged period the time. Our measurement however, does not include precise estimates of frequency and duration, specified in the DSM-V definition, which requires symptoms to be present between 75 and $100 \%$ of the time for a minimum of 6 months [9]. As mentioned above, we also recognize an important difference between sexual distress and dysfunctions causing a problem for an individual's sexuality.

While we assessed the association between sexual dysfunctions and a number of sexual health indicators, we were not able to examine the association with contraceptive usage, the most proximate determinant of unintended pregnancy, due to the small number of youth with an unmet need for contraception $(n=9$ females and $n=8$ males). Likewise, the small percentage of youth engaged in casual sex at last intercourse did not allow for a meaningful exploration of condom use at last sexual intercourse. Small sample sizes also limited the interpretation of results related to forced sexual intercourse.

Because this study was based on cross sectional data, we cannot establish causality. Further research using longitudinal design is needed to ascertain the persistence of sexual dysfunction and sexual dysfunction hindering sexuality over time and their predictive effect on other domains of sexual health. Further investigation is also needed to describe the socio-demographic and contextual factors related to sexual dysfunction and dysfunction hindering sexuality with specific emphasis on partnerrelated factors given the diversity of relationship experiences in adolescence and early adulthood.

\section{Conclusion}

While most youth in France enjoy a healthy sexual life, sexual dysfunctions are common, especially among females. Public health and clinical programs should screen for and address sexual dysfunction, which substantially reduces youth sexual wellbeing and are related to other common sexual health concerns among youth including STIs and unintended pregnancies.

Abbreviations

DSM-V: Diagnostic and statistical manual of mental disorders; FECOND: French National Fertility Survey; ICD-10: International statistical classification of diseases and related health problems (10th revision); Natsal: National survey of sexual attitudes and lifestyles; STI: Sexually Transmitted Infection; WHO: World Health Organization

\section{Acknowledgements}

We thank all women and men who participated in the FECOND survey.

\section{Funding}

This work was supported by a grant from the French Ministry of Health, a grant from the French National Agency of Research (\#ANR-08-BLAN-0286-01), and funding from National Institute of Health and Medical Research (INSERM) and the National Institute for Demographic Research (INED) Caroline Moreau is also supported by the William Robertson endowment funds and Robert Blum through the William H. Gates Sr. endowment.

\section{Availability of data and materials}

The dataset supporting the conclusions of this article is available upon request by contacting the corresponding author.

\section{Authors' contributions}

CM conceptualised the study, conducted the analysis and drafted the manuscript. AEK helped conceptualise the study including the analysis, wrote parts of the manuscript, and provided extensive revisions to the text. RWB contributed to the analytical strategy, provided critical review of drafts for intellectual content, and edited the text. All authors read and approve of the final manuscript.

\section{Competing interest}

The authors declare that they have no competing interests.

\section{Consent for publication}

Not applicable.

Ethics approval and consent to participate

The FECOND study was approved by the French Commission Nationale de I'Informatique et des Libertés and the current secondary analysis was approved by the Bloomberg School of Public Health Institutional Review Board at Johns Hopkins University.

\section{Author details}

'Department of Population, Family and Reproductive Health, Johns Hopkins Bloomberg School of Public Health, 615 North Wolfe Street, Baltimore, MD 21205, USA. ${ }^{2}$ Gender, Sexual and Reproductive Health, CESP Centre for research in Epidemiology and Population Health, U1018, Inserm, F-94807, Kremlin Bicêtre, INED, F-75020 Paris, France. 
Received: 19 March 2016 Accepted: 15 November 2016

Published online: 18 November 2016

\section{References}

1. World Health Organization. Sexual Health. (2012). Retrieved on 30 November 2012 from http://www.who.int/reproductivehealth/topics/sexual_ health/sh_definitions/en/

2. Gore FM, Bloem PJ, Patton GC, Ferguson J, Joseph V, Coffey C, Sawyer SM, Mathers CD. Global burden of disease in young people aged 10-24 years: a systematic analysis. Lancet. 2011;377:2093-102.

3. Tolman D, McClelland S. Normative sexuality development in adolescence: a decade in review, 2000-2009. J Res Adolesc. 2011;21:242-55.

4. Wellings K, Mitchell K, Collumbien M. Sexual health: a public health perspective. London: Open University Press; 2012.

5. Laumann EO, Nicolosi A, Glasser DB, Paik A, Gingell C, Moreira E, Wang T, GSSAB Investigators' Group. Sexual problems among women and men aged 40-80 y: prevalence and correlates identified in the Global Study of Sexual Attitudes and Behaviors. Int J Impot Res. 2005;17:39-57.

6. McCabe MP, Sharlip ID, Atalla E, Balon R, Fisher AD, Laumann E, Lee SW, Lewis R, Segraves RT. Definitions of sexual dysfunctions in women and men: a consensus statement from the fourth international consultation on sexual medicine. J Sex Med. 2016;13:135e-143.

7. World Health Organization. International statistical classification of diseases and related health problems. 10th ed. Geneva: World Health Organization; 1992.

8. Masters WH, Johnson VE. Human sexual response. Boston: Little, Brown; 1966

9. Kaplan HS. The new sex therapy. New York: Brunner/Mazel; 1974.

10. IsHak WW, Tobia G. DSM 5 changes in diagnostic criteria of sexual dysfunctions. Reprod Sys Sexual Disorders. 2013;2:122. doi:10.4172/2161-038X.1000122.

11. Hendrickx L, Luk Gijs L, Enzlin P. Distress, sexual dysfunctions, and DSM: dialogue at cross purposes? J Sex Med. 2013;10:630-41.

12. Mitchell K, Ploubidis G, Datta J, Wellings K. The Natsal-SF: a validated measure of sexual function for use in community surveys. Eur J Epidemiol. 2012;27:409-18.

13. Rosen R, Brown C, Heiman J, Leiblum S, Meston C, Shabsigh R, Ferguson D, D'Agostino Jr R. The Female Sexual Function Index (FSFI): A multidimensional self-report instrument for the assessment of female sexual function. J Sex Marital Ther. 2000;26:191-208.

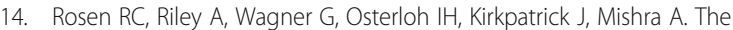
International Index of Erectile Function (IIEF): a multidimensional scale for assessment of erectile dysfunction. Urology. 1997:49:822-30.

15. McCabe MP, Sharlip ID, Lewis R, Atalla E, Balon R, Fisher AD, Laumann E, Lee SW, Segraves RT. Incidence and prevalence of sexual dysfunction in women and men: a consensus statement from the fourth international consultation on sexual medicine. J Sex Med. 2016;13:144e-152.

16 Shifren JL, Monz BU, Russo PA, Segreti A, Johannes CB. Sexual problems and distress in United States women: Prevalence and correlates. Obstet Gynecol. 2008;112:970-8.

17 Ahern NR, Kiehl EM. Adolescent sexual health and practice: a review of the literature - implications for healthcare providers, educators, and policy makers. Fam Community Health. 2006;29:299-315.

18 O'Sullivan LF, Brotto LA, Byers ES, Majerovich JA, Wuest JA. Prevalence and characteristics of sexual functioning among sexually experienced middle to late adolescents. J Sex Med. 2014;11:630-41.

19 Mitchell KR, Mercer $\mathrm{CH}$, Ploubidis GB, et al. Sexual function in Britain: findings from the third National survey of sexual attitudes and lifestyles (Natsal-3). Lancet. 2013;382:1817-29.

20 Hendrickx M, Gijs L, Enzlin P. Age-related prevalence rates of sexual difficulties, sexual dysfunctions, and sexual distress in heterosexual women: results from an online survey in Flanders. J Sex Med. 2015;12:424-35.

21 Mitchell KM, Wellings K. Measuring sexual function in community surveys : development of a conceptual framework. J Sex Res. 2013;50(1):17-28.

22 Legleye S, Charrance G, Razafindratsima N, Bohet A, Bajos N, Moreau C. Improving survey participation cost effectiveness of callbacks to refusals and increased call attempts in a national telephone survey in France. Public Opin Q. 2013;77:666-95.

23 Levinson S. Difficulties with sexual function: contexts, determinants and meanings. In: Bajos N, Bozon M, editors. Sexuality in France (p449-468). Oxford: Bardwell Press; 2012. Originally published 2008.

24 Mykletun A, Dahl AA, O'Leary MP, Fosså SD. Assessment of male sexual function by the Brief Sexual Function Inventory. BJU Int. 2006;97:316-23.

\section{Submit your next manuscript to BioMed Central and we will help you at every step:}

- We accept pre-submission inquiries

- Our selector tool helps you to find the most relevant journal

- We provide round the clock customer support

- Convenient online submission

- Thorough peer review

- Inclusion in PubMed and all major indexing services

- Maximum visibility for your research

Submit your manuscript at www.biomedcentral.com/submit 